\title{
When Average Joe met the Inexperienced Superstar-a case study of the consequences for a university of a partnership with IKEA
}

\author{
Eugenia Perez Vico ${ }^{1}$ (1) \\ Published online: 7 July 2020 \\ (C) The Author(s) 2020
}

\begin{abstract}
The aim of this study was to explore how consequences from a university-wide partnership unfolded at various levels within a university and induced intra-organizational dynamics. This was achieved via an in-depth investigation of "The Bridge," a collaborative partnership between the young mid-range Swedish Linnaeus University ("Average Joe") and the home furnishing retail giant IKEA, which despite its global reach has only limited research capacity (the "Inexperienced Superstar"). Based on previous research that conceptualizes consequences of collaborations as changes in wide-ranging resource categories over time, this article develops a conceptual framework that advances the understanding of the consequences of collaborative efforts at both the level of faculty individuals and groups, as well as on a university-wide level. The study identified both differences and similarities between the two levels related to material, knowledge, and social resource mobilization, and revealed consequent tensions within the university due to an imbalance in material resource mobilization and social resource mobilization. The resource-based multi-level perspective that this study puts forward enables a more finegrained and dynamic understanding of the conditions for undertaking and organizing university-wide long-term collaborative efforts.
\end{abstract}

Keywords University-industry · Consequences · Outreach · Technology transfer · Academic engagement $\cdot$ Resource-based view $\cdot$ University management

\section{Introduction}

Contemporary universities are deepening their efforts to engage with actors outside of academia (Pinheiro et al. 2015a, 2015b). In addition to well-recognized societal benefits, these efforts have consequences in terms of creating, giving access to, and consuming the tangible

Eugenia Perez Vico

Eugenia.perez_vico@fek.lu.se

1 Research Policy Group, Department of Business Administration, Lund University, Lund, Sweden 
and intangible resources that academics continuously require in order to pursue their core activities (Perez Vico and Hallonsten 2017). These consequences unfold variously on different levels within universities. On the level of faculty individuals and groups, they may enrich the scholarly work of teachers and researchers through input of funds, infrastructure, and knowledge (Perez Vico and Hallonsten 2019). However, collaborative activities require time and efforts to identify common interests and build up mutual understanding and trust among partners (Tartari and Breschi 2012; Perkmann and Walsh 2009). On the university-wide level, societal collaboration represents opportunities to strengthen the university's visibility, but also has implications for resource dependencies and appropriation of knowledge that may present challenges for the public good character of research and education (Pinheiro et al. 2015a, $2015 b)$. The variety of ways in which these resources are mobilized on different levels may create not just opportunities but also internal tensions, such as when university top management see significant university-wide benefits and set up collaborative arrangements that put pressure on faculty to engage even in the perceived absence of individual level benefits (Perez Vico and Hallonsten 2017; Broström et al. 2019).

Currently, university leadership increasingly induces and formalizes university-wide collaborative efforts with actors outside of academia (Pinheiro et al. 2015a, 2015b). This is partly driven by external pressures that create aspirations among university managements to signal that they are willing and able to collaborate with external actors, and subsequently increase their chances to strengthen their branding and competitiveness while reducing their dependence on state resources. However, the actual undertaking of university-wide collaborative efforts induced and organized by top management is critically dependent on faculty engagement (Broström et al. 2019). Thus, in order to better understand the conditions for undertaking and organizing university-wide collaborative efforts, it is important to capture and explain how various consequences stemming from such efforts affect actors operating at different organizational levels including both faculty individuals and groups as well as university-wide.

A large body of research studying the extent, modes, antecedents, and consequences of collaboration has accompanied the broadening of collaborative efforts of universities (for a review, see Perkmann et al. 2013; Bozeman and Boardman 2014). However, these studies have limitations related to understanding the conditions for undertaking and organizing university-wide collaborative efforts. First, this research has focused primarily on the consequences for collaborating actors outside of academia. Second, most of these studies build on quantitative measurements, and so have limited explanatory power when it comes to less quantifiable consequences (Larsen 2011; Perez Vico and Hallonsten 2017). Third, scholarly attention has chiefly been directed to interactions between strong research universities and industrial partners with significant research experience. Collaborative efforts among mid-range universities and external actors who hold limited research capacity have been largely ignored (Wright et al. 2008). This particular type of partner constellation is essential for regional development worldwide, yet it presents different conditions for collaboration and joint knowledge development than those on which existing research is chiefly based. While research capability is not a necessary prerequisite for a successful university-industry partnership in general, it is important for a partnership that includes joint research efforts (Azagra-Caro et al. 2006). Fourth, few studies have captured how the consequences of collaborative efforts occur at different organizational levels and the subsequent intra-organizational dynamics that might occur within the university. Moreover, none of these studies account for consequences in terms of how resources that academics continuously require in order to pursue their core activities are subsequently created, acquired, accessed, lost, and consumed over time as a result of a collaborative effort. 
In light of these limitations, the aim of the present study was to explore how consequences from a university-wide partnership unfolded at various levels within a university and induced intra-organizational dynamics. This was achieved via an in-depth investigation of "The Bridge," a collaborative partnership between the young mid-range Swedish Linnaeus University ("Average Joe") and the home furnishing retail giant IKEA, which despite its global reach has only limited research capacity (the "Inexperienced Superstar"). Based on previous research that conceptualizes consequences of collaborations as changes in wide-ranging resource categories that unfold over time, the present article develops a conceptual framework that advances our understanding of the consequences of collaborative efforts at both the level of faculty individuals and groups as well as on the university-wide level. Unlike frameworks that consider resources solely as an input to a collaborative effort, this conceptual framework focuses on resource mobilization in terms of how resources are subsequently created, acquired, accessed, lost, and consumed over time as a result of the effort. Through this novel approach, the study offers meticulously accounts of the many ways in which consequences from a partnership unfold at various levels within a university and paves the way for explicating subsequent intra-organizational dynamics. The study makes theoretical contributions that complement contemporary studies of university-industry interaction by offering a multilevel resource-based perspective that allows ordering and unpacking of consequences, thus paving the way for understanding the complex unfolding of such collaborative efforts.

In the next section, I will discuss previous studies and outline an analytical framework for the study of multi-level consequences from industrial collaboration. I will then describe the present method and design, and will follow this with a discussion of findings from the case study. Finally, I will summarize the contributions and implications of this study.

\section{Multi-level resource mobilization for universities from industrial collaboration}

Although existing research show that university-industry interactions have distinctive consequences for universities, there are, to the best of my knowledge, no studies that account for consequences in terms of resource mobilization at different organizational levels. However, there are a few that deal with the overall consequences for universities related to internal dynamics stemming from university-wide industrial collaboration. Broström et al. (2019) put forward a useful conceptualization of formalized university-wide collaborative efforts referred to as structured relations. Drawing on collective action theory, the authors describe how these efforts include an individual dilemma concerning the choice between contributing positively to university-wide consequences by sharing external relations, or keeping these relations to oneself and reaping individual-level benefits. One aspect of this dilemma is thus the discrepancy in how consequences unfold individually and collectively. Similarly, a study exploring how Swedish universities integrate the three missions identified internal tensions stemming from how university management orchestrated collaborative arrangements when identifying significant benefits and put pressure on faculty to engage even in the perceived absence of individual-level benefits (Perez Vico and Hallonsten 2017).

These studies point to the need to systematically capture how consequences in terms of cost and benefits from new collaborative efforts unfold both on the level of faculty individuals and groups (affecting teachers and researchers), and on the university-wide level (including collective organizational-wide consequences often apparent to top university management). 
Perez Vico and Hallonsten (2017) recently offered a conceptual framework for organizing consequences through resource categories that draw on traditions in organization theory and innovation studies. Resource-based perspectives are well recognized in the study of interorganizational relations (e.g., Dyer and Singh 1998; Gulati 1999), with contributions particularly related to research collaboration (e.g., Hagedoorn et al. 2000), and have also been applied by sociologists to explain the social organization of science (Merton 1973; Bourdieu 1975). Drawing on Perez Vico and Hallonsten (2017), I define resources as the wide-ranging assets that academics accumulate and utilize in order to pursue their core activities. The consequences of collaboration can thus be conceptualized in terms of resource mobilization; that is, how resources are created, acquired, accessed, lost, and consumed as a result of a collaborative effort. This perspective chiefly on how sociologists of science describe processes of change in resources. For instance, Bourdieu (1975) acknowledges peer-recognition as a resource and denotes it as a form of social capital that is reconverted into more tangible forms of capital, and Hagstrom (1965) describes resource transactions between scientists where resources take the form of information, recognition, and funding.

The framework by Perez Vico and Hallonsten (2017) has proven to be useful in studying the consequences of collaborative academic work (e.g., Perez Vico and Hallonsten 2019; Perez Vico 2014). Thus, drawing on this framework, the analysis in this study is structured around three categories that include positive and negative mobilization of resources.

Material resources involve tangible assets of use for contemporary academics. Sociologists of science have pointed to the need of financial and physical resources in the scientific realm to pay salaries and acquire equipment (e.g., Bourdieu 1975; Parsons and Platt 1973). Material resources also include access to data, research objects, real-life test environments, and manpower (Hagedoorn et al. 2000). On the level of faculty individuals and groups, this may include research instruments and test environments (Perez Vico and Hallonsten 2019), manpower for education ( $\mathrm{Lin}$ and Bozeman 2006), and costs related to bridging differences in logics and creating common understanding (Tartari and Breschi 2012). On the university-wide level, it may include attracting funds (Geuna 2001) as well as the costs of building capability for managing an increasing set of stakeholders (Jongbloed et al. 2008) and dealing with intraorganizational tensions stemming from contradictory expectations (Geuna 2001). In research, these expectations take the form of parallel calls for both higher societal relevance and research excellence. In education, tensions stem from the simultaneous need for direct societal relevance and close connection to research (Ek et al. 2013). These expectations pose particular challenges to mid-range universities, which are especially resource constrained and struggle with creating critical mass in research along with societal embeddedness (Wright et al. 2008).

Knowledge resources concern the stock of scientific, technological, and other types of knowledge that are often intangible by nature, embodied in individuals and mobilized through learning, and that may lay the foundation for future discoveries (Merton 1973). Hagedoorn et al. (2000) denote scientific and technological knowledge as an intangible asset and the exchange and collaborative build-up of this resource is a key rationale for inter-organizational research collaboration (Hagedoorn et al. 2000). This knowledge may also be embodied in individuals and organizations as competence and capability, and materialized in books, articles, patents, frameworks, or other artifacts. On the level of faculty individuals and groups, it may include co-created insights, feedback, and inspiration from applications of value to both research (Jacobsson et al. 2014) and education (Plewa et al. 2015), as well as the development of skills for collaboration (Perez Vico 2014). However, dependencies that develop through close collaboration may narrow the mobilization of knowledge resources since these 
complicate disinterested knowledge development for the good of a wide public (Perez Vico and Hallonsten 2019). On university-wide level, knowledge resources may include developing top management skills that create self-reinforcing university-wide collaborative capabilities (Arza 2010). Yet, university management may subsequently adopt industry-adapted cognitive frames that limit capabilities for organizing public-good research and education (Slaughter et al. 2002).

Social resources refer to the informal interpersonal aspects of relationships, which comprise assets related to the development and maintenance of networks, social appreciation, and legitimacy both within and outside the particular collaboration (Bourdieu 1975; Coleman 1990). On the level of faculty individuals and groups, this may include developing the valuable mutual trust and understanding with industrial partners which creates advantages given the increased requests for collaboration that contemporary academics are faced with (Perez Vico and Hallonsten 2019), but also legitimacy issues due to dependencies related to both research (Perkmann and Walsh 2009) and education (Gluck et al. 1987). On university-wide level, it may involve developing strong external networks, visibility, and societal legitimacy (Arza 2010); however, there are also legitimacy risks related to dependency on a university-wide level (Jongbloed et al. 2008).

Although these resource categories are distinct, they are mediated in connection to one another, and one type of resource can be traded for or used to enable the mobilization of other resources (e.g., social resources in the form of recognition can be used to obtain material resources in the form of economic capital). Also, a certain aspect of a collaboration, such as integrity concerns, may lead to consequences on several resource categories, such as restrictions in knowledge development or loss of social appreciation in certain spheres. By distinguishing the collaboration-induced resource mobilization on the level of faculty individuals and groups from that on the university-wide level, this section puts forward a suitable frame for structuring the analysis of the study. This analytical frame enables a more finegrained understanding of the consequences of a collaborative partnership that allows exploring intra-organizational tensions stemming from disparities in resource dynamics on various levels.

\section{Research design and method}

The exploratory purpose of this study required an in-depth case study, which was provided by The Bridge, a partnership between Linnaeus University (LNU) and IKEA. LNU is a Swedish public university with 2000 employees and approximately 15,000 full-time students. It was formed in 2010 by the merger of a smaller university and a university college, and is characterized by strong regional embeddedness and responsiveness. LNU's ratio between revenues to research and education is 7/3 (Linnaeus University 2019), and its research and education performance is average compared to other Swedish higher education institutions. IKEA was founded in 1943 by Ingvar Kamprad in the same region as LNU. It operates worldwide, and has approximately 400 stores in 50 countries (Inter IKEA Systems 2019). This globally renowned industry leader is controlled by a foundation, and the business is characterized by an emphasis on cost awareness, innovative solutions, and continuous product development (Jonsson and Foss 2011; Vahlne and Jonsson 2017). IKEA has significant experience of working with student recruitment and placements, commissioned thesis work, and contract research, but only limited experience of collaborative research. 
The Bridge provided a unique opportunity to study a university-wide collaboration with a new partner involving relatively little interference from external factors such as requirements attached to third-party funding. While most studies of university-industry partnerships include government-supported activities where efforts evolve under imposed requirements (Perkmann and Walsh 2009), this case offered an opportunity to study resource mobilization from the start and in a situation that is relatively independent of external pressures. The analysis covers the unfolding consequences of the partnership from its inception in 2009 to the spring of 2017 when data were gathered.

\section{Data collection and analysis}

The study was based on rich data from multiple sources (see Appendix A for an overview of data sources and uses). Central to the analysis were 27 in-depth semi-structured interviews with 25 individuals conducted in 2017, making up $40 \mathrm{~h}$ of material (see Appendix B for details). These individuals included five LNU permanent faculty members, two PhD students, three prefects, three deans, the current and former president, and three central staff functions, and covered all relevant faculties and positions. Central personnel at IKEA (four managers, two adjunct professors, and the former CEO) with insight into the conditions for the collaboration and consequences for LNU were also interviewed as a means of triangulation. The interviews included open questions about the evolution of collaborative efforts in terms of organization, individual involvement, and perceived consequences. All but five interviews were conducted in Swedish, all but four were conducted face-to-face, and all were transcribed. The interview data were supplemented with meeting notes, e-mail correspondence, formal and strategic documents (e.g., agreements and declarations), yearly activity plans, internal evaluations, documentation from workshops, informal memos, marketing material, and media coverage.

The analysis was conducted with the help of the NVivo software package in four steps following an abductive coding approach (Dubois and Gadde 2002). First, the complete data set (except workshop notes, as these were collected later on) was structured chronologically, thematically, and in relation to type of source, events, and actor, in order to gain an overview of the development of and conditions for the partnership. Second, a data-centric open coding was conducted focusing on consequences and intra-organizational tensions; this produced unstructured codes. Third, codes related to consequences were assigned to one of the two levels of analysis and one of the resource categories. Fourth, the structured data was used to search for different patterns in consequences related to level of analysis, themes, events, and intra-organizational tensions. This included establishing causality between an event related to the collaboration, a subsequent consequence, and tensions. Connections provided by the interviewees in their accounts and captured in other type of data were crucial for this. During the interviews, respondents were asked to reflect on the issue of additionality; that is, whether a consequence could have emerged in the absence of the collaboration.

The large variation of data sources allowed for triangulation of findings. In addition, a 3-h interpretation workshop with six key actors of the partnership was organized to clarify, confirm, or revise a preliminary analysis.

\section{Research setting: the evolution of The Bridge}

The Bridge was initiated in 2009 following a large donation from IKEA's founder. The aim, as formulated in 2016, was to create a "mutually rewarding and long-term sustainable partnership 
[...] attracting, retaining and developing key competences and future talents thus positioning Linnaeus University globally". A co-operation council with three persons from each organization was installed "to determine the objectives for the activities [...] and to follow up that the activities at Linnaeus University are conducted in accordance with the purpose". While this was not an unrestricted donation, funds were largely used for traditional research positions.

The partnership agreement was set up hastily, and both sides were rather unprepared but enthusiastic. IKEA perceived the donation to be a low-risk opportunity since the funds come from the founder and not the company budget, and LNU was grateful for the significant endowment and excited to work with a world-class company.

Soon the IKEA founder handed over responsibility for the partnership to IKEA managers. The founder was rather disconnected from daily company operations at the time, and the managers were puzzled about the intent of the partnership. Indeed, IKEA had little experience with this type of university collaboration:

When I was employed [at IKEA] in 1998, I was the first to have a PhD. [IKEA] does not have a research and development environment of its own, and so there's no environment where the company can match a collaborative effort. (IKEA staff 1)

Around 2011, the professorship was inaugurated via the appointment of a professor with a social science profile, who then started to build up a research group. The funds were also used for technical science positions, but the interdisciplinary ambitions did not materialize as the two groups evolved separately. While the newly employed researchers were just starting, IKEA management wanted to link the collaboration more closely to operations; and based on experiences as research procurers, they expected results:

We did not have much experience of working with universities [...] we wanted to engage the whole company in this, and many were expecting results in a year or so. But we learnt that these things take time; it can take ten to fifteen years [...] but it was a journey to get to that point, to understand that. (IKEA staff 2)

Disagreements emerged in the council, as LNU management did not share these expectations:

There were quite high expectations from both sides, but these were, well, apparently, rather unspoken, and that led to a lot of frustration [...] there was a perception within IKEA that they had not got enough out of the money. ( $L N U$ top manager 2)

The expectations were projected onto the professorship, and soon differences surfaced in perceptions of expected results and working methods between the professor and several council members. When IKEA management perceived that few research results materialized, they shifted the attention to education; LNU answered by developing a master's program that started in 2014 and responded to IKEA's personnel needs. Education was a new focus for the partnership, since the donation had previously been used for research positions. However, the development of the program was financed not by the donation but by university funds.

By 2014, IKEA managers perceived a lack of overview and a program management was installed. A clearer vision was developed and linked to the operational level through plans and reports. When data collection for this study was conducted in 2017, over 100 persons from both organizations had been engaged in activities related to the Bridge. 


\section{Multi-level resource mobilization stemming from The Bridge and consequent intra-organizational dynamics}

Findings from the case study will be discussed in the following sections, following the conceptual framework with its focus on three resource categories at the two levels, and consequent tensions.

\section{Resource mobilization on university-wide level}

\section{Material resources}

Already at an early stage in the establishment of the partnership, the unique access to a resourceful partner was pointed out as the most significant positive university-wide material resource:

This is a fantastic endowment [...] but beyond that it's so much more. [The partnership] stands out, not only within the university but also in relation to our sister universities. We now have open doors to a very interesting partner. ( $L N U$ top manager 2)

However, with time, top management perceived significant negative university-wide material resource mobilization. The costs for setting up supportive functions were substantial. LNU management rejected the suggestion from IKEA that LNU should match the donation financially to secure mutual engagement, but the university did fund partnership support functions, although these were chiefly mobilized halfway through the partnership. There was a consensus among top LNU management that the establishment of the collaboration had been very laborious in relation to both internal and external anchoring, particularly some year into the partnership when operational activities were initiated:

There were such different views on what this [collaboration] was, both between us and IKEA but also within the university. We naïvely thought that the money was enough to get people [at LNU] to commit, but so much more than that was needed. Nothing has run smoothly; there have been so many problems. We [the management] have had lots of meetings, engagements, negotiations, mediating between different people and interests, meetings back and forth and back again, and we have been questioned and yelled at from all angles. (LNU top manager 1)

Thus, top management perceived university-wide costs for handling diverging logics within The Bridge but also costs for building up intra-organizational legitimacy for the partnership and significant costs for managing collaborative education that met the needs of IKEA. The master's program demanded significant financial resources and management efforts, chiefly for establishing engagement among a wider set of teachers, interfaculty coordination, and managing IKEA's engagement in the program.

\section{Knowledge resources}

Some years into the partnership, LNU management perceived significant development of competence for collaborating with a strong yet academically rather inexperienced actor: 
We now know how IKEA works and we know what to expect from them [...] and how we can manage this relationship. We challenged ourselves with IKEA, with a tough partner, and we came out more confident. (LNU top manager 3)

Top management also welcomed the university-wide guidance through insights into outsideworld perspectives of relevance to the university role, and related learnings from being challenged as an organization:

There's often something self-righteous at universities, that we know so much ourselves, but we have so much more to learn than we think, and there's so much we can gain from learning. IKEA is constantly searching, and if we try to match their pace we'll be challenged and we'll develop. They have this way of constantly questioning us from new angles, like common sense; in a way, it's like being academically scrutinized. (LNU top manager 2)

With time, these insights offered opportunities for creating university-wide focus:

We now see this as a great opportunity for articulating relevance and underpinning a focus for the whole university. We know we aren't yet an internationally renowned comprehensive university, but by critically listening to our partner we can map out an interesting and unique direction to become one. (LNU top manager 2)

In 2011, discussions emerged about a non-disclosure agreement (NDA). At this point, top management perceived this as restrictions on knowledge diffusion due to secrecy that potentially affected the mobilization of knowledge resources university-wide. Although the NDA was considered to be researcher-friendly, management expressed concerns about not finding an agreement with IKEA on an organizational level and resulting restrictions on knowledge diffusion:

We tried to find the right level between free results and IKEA's needs, but this is something unfinished, and now we see that not everyone wants to sign the individual NDA, and that's a problem [...] it appears to be too restrictive for researchers. (LNU top manager 3)

The parties could not agree on a university-wide NDA, and IKEA approached researchers and students individually.

\section{Social resources}

In a later phase of the partnership, it became clear that gaining a commitment from a worldrenowned and resourceful actor such as IKEA gave LNU recognition as a capable collaborative partner:

It's a quality check to have this collaboration, to show that you stand side by side with an actor like this and be a worthy partner. (LNU top manager 4).

The progress of the partnership also created social inter-partner resources. Top management at both IKEA and LNU perceived that they had developed strong mutual trust and understanding, though this took time. While this assured a commitment that enabled university-wide access to a resourceful partner, there were diverging perceptions about how institutionalized these resources were. Indeed, trust proved to be an issue according to LNU managers, given its 
person-to-person-based character and the substantial staff turnover rate at IKEA throughout the partnership. Still, there were indications of an increasing institutionalization of trust over time:

After these years and all we have gone through, we see that confidence is no longer just about the individuals, but there's something inherent in the organizations now; we see well-established connections on various levels in both organizations. And there's still the shared regional heritage. (LNU top manager 1)

Halfway through the partnership, when collaboration in education was initiated, there were significant increases in university-wide attractiveness to students as the master's program had a strong signaling value. However, throughout the partnership, several LNU employees feared legitimacy loss due to perceived dependency and lack of integrity on an organizational level:

There may be questions about when this becomes a frivolous university; we have to be aware of that. You might become dependent on a funding source that could suddenly change direction, or be convicted of child labour, or accused of having a history of Nazi sympathy. (LNU top manager 2)

\section{Resource mobilization on the level of faculty individuals and groups}

\section{Material resources}

From start, the endowment itself was a key resource for research funding for faculty, as it was chiefly used for faculty positions, particularly in social science. At its largest in 2016, the social science group consisted of one professor, three doctoral students, and two postdocs, all of whom were mainly financed through the endowment. In addition, the group perceived itself as having unique access to a resourceful partner, not only as a research object but also as protected space for collaboration:

Bridge has been a liminal space for pushing boundaries [...] that has given me an awful lot. The obvious is the funding [... but it also] has allowed us to walk together with IKEA in a unique way in terms of collaboration that not only includes the access to data, but extreme closeness and trust. (LNU faculty 1).

For the technology group, the partnership enabled recruitment of two doctoral students (in 2012 and 2014), granted seed money for establishing relations, and mobilized an adjunct IKEA professor providing supplementary manpower for teaching. Some researchers perceived the access to IKEA laboratory equipment and data to be critical, while others felt the funding was the only relevant material resource. The partnership also included the area of design, where an adjunct IKEA professor again came to provide significant manpower for teaching. Research efforts were few due to internal challenges in LNU's design division, but in 2017, relationship-building activities took off and two $\mathrm{PhD}$ positions were announced.

The most noticeable negative material resource mobilization unfolded in 2013 and included costs for developing and providing collaborative education through the master's program. Although this was generally described as successful, and even though IKEA provided manpower in the form of teachers, supervisors, and access to complementary resources, the relevant faculty felt that interacting with IKEA and answering the call for multidisciplinarity by mixing students 
from different disciplines was resource consuming. There was little overlap between individuals benefiting from the endowment and those bearing the costs of the development of the program:

It's been costly for us, and some individuals have put in fantastic efforts, in terms of time and dedication, but also emotionally [...] But they are not the people getting the IKEA money [...] This type of programme where we combine teaching staff from different faculties is new; we had to develop solutions for that, which proved to be challenging, and then we had to handle IKEA on top, which is amazing of course, but yes, it's been very hard. (LNU faculty 2)

Relatedly, some researchers emphasized the costs of handling diverging logics and perceptions, in particular when facing IKEA's expectation of fast and tangible results, and given IKEA's limited research capacity:

It's not easy to build a research collaboration, to work together in knowledge development with an organization where research is a negative-sounding word $[\ldots]$ and they want clear solutions to their problems [...] you have to invest a lot of time and effort into paving the way. (LNU faculty 3)

However, others did not perceive it to be particularly costly to establish research relations with IKEA, particularly given the size of the endowment.

\section{Knowledge resources}

With time, several faculty members perceived significant guidance through insights into outside-world perspectives that enriched both research and education. In terms of research, faculty members, particularly in technology, underlined the value of acquiring feedback on theoretical models and hypotheses which according to some researchers created many interesting results and increased the relevance. In terms of education, insights strengthened relevance:

[Students] get first-hand feedback and insight into the workings of a global company [... By seeing IKEA and LNU teachers work together] the students learn to understand the difference between the theoretical and the practical perspective - that's the strongest pedagogical contribution. (LNU faculty 6)

Teachers thus perceived mutual knowledge development that took the form of new educational modes, such as cross-disciplinary project work and thematic teaching modules where practical and theoretical perspectives were discussed jointly. Some researchers also described mutual knowledge development including joint problem formulation and co-creation with relevant connection to IKEA's activities, although this took many years to establish. Others indicated that joint knowledge development was a challenge given IKEA's limited research capacity, and that there had been only a modest amount of collaborative knowledge development within concerned faculty groups. Furthermore, collaboration with a large company was not entirely unproblematic in the research tradition within which some faculty operated:

I do not do research with IKEA, I would not say that, and I do not think they understand it in that way either [...] when I go to IKEA I get some sort of inspiration, but it's not like they are some sort of stakeholder, but of course the money comes from IKEA, but 
it's not like they can tell me what to do $[\ldots]$ of course they have the knowledge and $[\ldots]$ they have made me think about things differently, but it's not like they influence my research. (LNU faculty 4)

As partnership activities were conducted, some teachers and researchers also noticed strengthened competence for collaborating, including knowledge on how to organize and conduct interdisciplinary work and collaborate with a large international company:

We've really developed our competence on how to work with a company and how to handle students from various disciplines and conditions. Before [the master programme] it was mostly about study visits and guest lectures. Now we know how to truly collaborate in education and to work with companies in a completely new way. ( $L N U$ faculty 3)

However, others felt they had already gained these skills from previous experiences.

Faculty members occasionally perceived restrictions on knowledge diffusion due to secrecy. Some of the researchers refused to sign IKEA's NDA, considering it to be a constraint, especially in relation to the work of students:

How can you have a collaboration where researchers and students cannot reveal their work due to secrecy? I do not see how we can work under such conditions, but maybe that is not a problem for others. But still, how will students be able to show the results of their work? (LNU faculty 6)

Still, others saw the NDA as a natural and necessary part of collaborative work, and considered it relatively unproblematic. To some extent, the difference in views stemmed from differences in research traditions.

\section{Social resources}

Perceptions of social resource mobilization varied, even within the same group. Many in the technology group experienced the development of mutual trust and understanding towards IKEA already at an early point. The collaboration was seen as a natural element, given their technological focus and strong tradition of industrial cooperation. These researchers stated that the resulting self-confidence and visibility created spillover effects and contributed to building critical mass:

The road is open in a new way; we now have the necessary contacts and there is trust capital. (LNU faculty 5)

The whole group, and even the department, is in a completely new phase [...] from threat of being closed down to lots of new recruitment and activities. (LNU faculty 3)

Nevertheless, halfway through the partnership, when the co-operation council introduced the program manager and formalized working modes (largely in response to IKEA's request), several interviewees saw this as decreased trust from IKEA:

I think many feel like IKEA want control now with the [programme] manager; first they let us work in a freer way, and now it feels like they do not trust us to do that anymore. (LNU faculty 4) 
Some researchers, particularly in the social science group, experienced legitimacy loss due to perceived dependency and lack of integrity. As already discussed, some researchers found collaboration with a large company to be rather problematic, and deliberately distanced themselves from IKEA. This was also indicated through missing acknowledgements in publications that were reported as results from the partnership. However, other researchers underlined the deep mutual trust that unfolded and did not perceive the legitimacy issues described previously.

Although there was some agreement on the increase in student attractiveness, several teachers experienced risks of legitimacy loss due to the domination of IKEA:

We have one of the biggest companies in the world with us, which is fantastic, yet we have to watch their presence. They'd love to bring students everywhere, and want to direct our activities in the programme, but we have to look after the students. This is not IKEA's programme; we have to educate free-thinking open-minded individuals and prepare them for a wide labour market, and there's a trade-off there. (LNU faculty 6)

\section{Tensions stemming from imbalance between consequences on various levels}

The previous descriptions reveal patterns of resource mobilization stemming from the IKEALNU collaboration on the two levels. Table 1 summarizes the patterns emerging in the previous two sections through themes related to resource mobilization.

Despite noticeable similarities in perceived resource mobilization at each level, there were also significant differences that induced four areas of tensions. The first tension concerned the imbalance in material resource mobilization. Significant negative university-wide material consequences unfolded when establishing the collaboration, while positive material resource mainly

Table 1 Overview of main themes related to resource mobilization

\begin{tabular}{|c|c|c|}
\hline & University-wide level & Level of faculty individuals and groups \\
\hline $\begin{array}{l}\text { Material } \\
\text { resources }\end{array}$ & $\begin{array}{l}\text { + Unique access to a resourceful partner } \\
\text { - Costs for setting up supportive functions } \\
\text { - Costs for handling diverging logics and } \\
\text { perceptions } \\
\text { - Costs for building up intra-organizational le- } \\
\text { gitimacy } \\
\text { - Costs for collaborative education }\end{array}$ & $\begin{array}{l}\text { + Research funding } \\
+ \text { Unique access to a resourceful partner } \\
+ \text { Manpower for teaching } \\
\text { - Costs for developing and providing } \\
\text { collaborative education } \\
\text { - Costs for handling diverging logics and } \\
\text { perceptions }\end{array}$ \\
\hline $\begin{array}{r}\text { Knowledge } \\
\text { resources }\end{array}$ & $\begin{array}{l}\text { + Competence for collaborating } \\
+ \text { Guidance through insights into } \\
\text { outside-world perspectives } \\
\text { - Restrictions on knowledge diffusion due to } \\
\quad \text { secrecy }\end{array}$ & $\begin{array}{l}\text { + Competence for collaborating } \\
\text { + Guidance through insights into } \\
\text { outside-world perspectives } \\
\text { + Mutual knowledge development } \\
\text { - Restrictions on knowledge diffusion due to } \\
\quad \text { secrecy }\end{array}$ \\
\hline $\begin{array}{l}\text { Social } \\
\text { resources }\end{array}$ & $\begin{array}{l}\text { + Recognition as a capable collaborative } \\
\text { partner } \\
+ \text { Mutual trust and understanding } \\
+ \text { Attractiveness to students } \\
\text { - Legitimacy loss due to perceived dependency } \\
\quad \text { and lack of integrity }\end{array}$ & $\begin{array}{l}\text { + Mutual trust and understanding } \\
\text { - Legitimacy loss due to perceived } \\
\text { dependency and lack of integrity }\end{array}$ \\
\hline
\end{tabular}

+ indicates created and/or acquired resources and - indicates lost and/or consumed resources. Similarities across the two levels are written in bold italics 
benefited faculty individuals and groups. As a consequence, LNU management expected significant knowledge development in term of publications, particularly in collaboration with IKEA, and university-wide knowledge spill-over effects. However, several actors on various levels felt that knowledge development was scarce and that the knowledge stayed with particular researchers. Thus, when expectations were not met, tensions arose. Faculty members, on their side, perceived that the format (i.e., an endowment funding traditional academic positions) was a poor fit with the expectations of top management on collaborative knowledge development:

I think [LNU] leadership has had a lot of expectations on collaborative and interdisciplinary research due to the size of the money, but they are not reasonable expectations since we were not given the right conditions. (LNU faculty 1)

A second tension concerned imbalance in social resource mobilization. While significant social resource benefits unfolded on university-wide level, consequences for faculty individuals and groups were more ambiguous. Some faculty perceived strengthened legitimacy, visibility, and relevance from collaborating with IKEA, but others experienced issues related to threatened objectivity and dependency. As a consequence, top management were puzzled by faculty members' tendency to maintain a distance from IKEA:

Of course there's a need for independence, but if you take the money, you know the conditions of the setup. [...] It's not Monsanto, but some [faculty] are acting like it is [...] There's some resistance because this [collaboration] is top-down initiated and we [management] think it's a good idea. (LNU top manager 1)

A third and related tension included the interplay between material and social resource mobilization. Significant university-wide material resources were spent on building up social resources on a university-wide level, which top management expected to pave the way for collaboration on operational level. However, this comparatively strong social resource mobilization on a university-wide level did not always transfer to the level of faculty individuals and groups. Consequently, while top management felt the material resources given to the faculty should be sufficient to establish collaboration, individual researchers and teachers felt that top management underestimated the effort:

The collaboration council expected us to get going after some symbolic seed money, but it does not work like that; it took us many years of groundwork to identify and create the right conditions for a collaboration. (LNU faculty 5)

\section{Concluding discussion and implications}

This study offers an illustrative case and a conceptual framework that meticulously captures the many ways in which the consequences of an industry collaboration, in terms of resource mobilization, unfold at various levels within a university, and identifies subsequent interorganizational tensions. By doing so, it makes several theoretical contributions of relevance to the study of university-industry collaboration.

First, the resource-based perspective that this study puts forward allows ordering and unpacking consequences in a way that enables a more fine-grained and dynamic understanding of university-industry interaction. Through conceptualizing long-term and sequential consequences as a process of qualitative change in resources, this study responds to the call for 
approaches to the study of university-industry interaction that hold higher explanatory power (Larsen 2011).

Second, while resource-based approaches are normally applied at either the organizational or individual level, the offered framework combines these and thus enables explicating consequent intra-organizational tensions. In this way, the study complements resource-based perspectives on the study of academia, such as those offered by scholars interested in research collaboration (e.g., Perez Vico and Hallonsten 2017; Hagedoorn et al. 2000) and by sociologists of science (e.g., Merton 1973; Bourdieu 1975).

Third, scholars have so far studied structured relations by drawing on collective action theory (Broström et al. 2019). The present study complements this conceptual frame by offering a multi-level resource-based perspective that allows ordering and unpacking of the consequences stemming from structured relations, thus paving the way for understanding the complex dynamics that characterize such collaborative efforts.

In addition, this study brings new contextual insights as it concerns collaboration between an industrial actor with less research experience and a mid-range university - a constellation that has been significantly ignored (Wright et al. 2008). This case illustrates how the challenges of bridging logics between university and academia are accentuated due to the limited research capacity of the industrial actor. The relationship was characterized by concerns that are well recognized in research on university-industry collaboration related to diverse time scales, confidentiality, autonomy, and appropriation. These concerns are particularly prominent in this case, as IKEA is relatively inexperienced in conducting research and working with a university in a research partnership. Moreover, there was an imbalance in terms of resources and recognition between the comparatively small and anonymous LNU and the world-renowned IKEA that increased the risk of unhealthy resource dependency on the part of the university.

Implications for university management can be drawn from this study. The case illustrates the importance of holding a coherent understanding of consequences on all levels and areas within a university when orchestrating a university-wide partnership. Lack of such insight may hinder the anchoring process which is necessary to realize such partnerships. The case also emphasizes that collaborating with a new and inexperienced actor will demand significant time and effort, beyond what is usually expected from a conventional university-industry partnership. Consequently, substantial resource investments will be a prerequisite for universities that wish to engage with new actors, even in the light of a significant potential for subsequent positive resource mobilization. Furthermore, the study demonstrates the significance of staffing continuity in partnerships since social resources are tied to specific interpersonal relationships and take time to build up. Finally, the case point to the importance of handling imbalance in terms of resources and recognition between partners as this can lead to unhealthy resource dependency.

The resource-based multi-level framework introduced in this study offers opportunities for future research that can deepen the understanding of university-industry interaction. The study is limited to understanding the consequences for one partner, thus future research could explore interaction dynamics as resource mobilization within and between several partners. This would provide a more complete picture of the unfolding of partnerships. Furthermore, given the contextdependency of these interactions, comparable studies ought to be carried out in other contextual settings.

Funding Information Open access funding provided by Lund University. 


\section{Appendix}

Appendix A The data sources and their uses

Data source Use in the study

Semi-structured interviews with:

LNU faculty: Permanent faculty (6), PhD students (2), and prefects (3)

LNU top management: The current and former president (2), central staff functions (3), and deans (3)

IKEA staff: Managers (4), adjunct professors (3), and the former CEO (1)

Due to ethical considerations, no further information on interviewees is provided, and these details are not connected to the listing in appendix B

Strategic documents: Agreements, declarations, and strategic plans (2009-2015)

Reporting documents: Yearly activity plans and reports (2011, 2016-2017), internal evaluation of the masters' program (2016), and formal meeting notes from the co-operation council (2009-2016)

Informal documents: E-mail correspondence (2014, 2015), documentation from workshops, and informal memos $(2013,2014)$

Communication material: Media coverage (2009-2017), information and marketing material and web page material (2017)

Workshop: Conducted over $3 \mathrm{~h}$ with six central individuals at LNU in 2017. All but two had previously been interviewed
Capturing various individuals' perceptions of activities, conditions, and consequences of the partnership, and the role of various actors

Capturing the formal setting that framed the partnership and preparing for interviews

Capturing the activities conducted within the partnership and perceptions of consequences, and identifying interviewees

Capturing the informal setting that framed the partnership and perceptions of consequences, identifying interviewees, and preparing for interviews

Preparing for interviews and capturing how consequences and developments were communicated externally to various audiences by various actors

Clarifying, confirming, or revising interpretations, and seeking supplementary clarifications 


\section{Appendix}

Appendix B Overview of conducted interviews

\begin{tabular}{|c|c|c|c|}
\hline $\begin{array}{l}\text { Reference in text, } \\
\text { position, and } \\
\text { organization }\end{array}$ & $\begin{array}{l}\text { Number of } \\
\text { interviews } \\
\text { (total of } 27 \text { ) }\end{array}$ & $\begin{array}{l}\text { Date of interview } \\
\text { (2017) }\end{array}$ & $\begin{array}{l}\text { Duration and medium } \\
\text { (total of } 2400 \mathrm{~min} \text { ) }\end{array}$ \\
\hline IKEA staff 1 & 2 & $\begin{array}{l}20 \text { February and } 13 \\
\text { March }\end{array}$ & $\begin{array}{l}60 \mathrm{~min} \text { and } 30 \mathrm{~min} \text {, } \\
\text { face-to-face }\end{array}$ \\
\hline IKEA staff 2 & 1 & 13 March & $60 \mathrm{~min}$, face-to-face \\
\hline IKEA staff 3 & 1 & 11 May & $45 \mathrm{~min}$, telephone \\
\hline IKEA staff 4 & 1 & 31 March & $60 \mathrm{~min}$, face-to-face \\
\hline IKEA staff 5 & 1 & 13 March & $75 \mathrm{~min}$, face-to-face \\
\hline IKEA staff 6 & 1 & 16 March & $75 \mathrm{~min}$, face-to-face \\
\hline IKEA staff 7 & 1 & 13 March & $75 \mathrm{~min}$, face-to-face \\
\hline $\begin{array}{l}\text { LNU central staff function } \\
\quad 1\end{array}$ & 1 & 28 February & $60 \mathrm{~min}$, face-to-face \\
\hline $\begin{array}{l}\text { LNU central staff function } \\
\quad 2\end{array}$ & 1 & 31 March & $30 \mathrm{~min}$, telephone \\
\hline $\begin{array}{l}\text { LNU central staff function } \\
\quad 3\end{array}$ & 1 & 27 February & $150 \mathrm{~min}$, face-to-face \\
\hline LNU faculty 1 & 2 & 10 and 22 March & $\begin{array}{l}60 \mathrm{~min} \text { and } 90 \mathrm{~min} \text {, } \\
\text { face-to-face }\end{array}$ \\
\hline LNU faculty 2 & 1 & 28 February & $45 \mathrm{~min}$, face-to-face \\
\hline LNU faculty 3 & 1 & 10 March & $60 \mathrm{~min}$, face-to-face \\
\hline LNU faculty 4 & 1 & 24 March & $60 \mathrm{~min}$, telephone \\
\hline LNU faculty 5 & 1 & 14 March & $75 \mathrm{~min}$, face-to-face \\
\hline LNU faculty 6 & 1 & 14 March & $90 \mathrm{~min}$, face-to-face \\
\hline LNU faculty 7 & 1 & 16 March & $60 \mathrm{~min}$, face-to-face \\
\hline LNU faculty 8 & 1 & $8 \mathrm{March}$ & $60 \mathrm{~min}$, telephone \\
\hline LNU faculty 9 & 1 & 14 March & $60 \mathrm{~min}$, face-to-face \\
\hline LNU top manager 1 & 1 & 27 February & $90 \mathrm{~min}$, face-to-face \\
\hline LNU top manager 2 & 1 & 31 March & $60 \mathrm{~min}$, face-to-face \\
\hline LNU top manager 3 & 1 & 31 March & $60 \mathrm{~min}$, face-to-face \\
\hline LNU top manager 4 & 1 & $31 \mathrm{March}$ & $90 \mathrm{~min}$, face-to-face \\
\hline LNU top manager 5 & 1 & 16 March & $60 \mathrm{~min}$, face-to-face \\
\hline LNU top manager 6 & 1 & 10 March & $60 \mathrm{~min}$, face-to-face \\
\hline
\end{tabular}


Open Access This article is licensed under a Creative Commons Attribution 4.0 International License, which permits use, sharing, adaptation, distribution and reproduction in any medium or format, as long as you give appropriate credit to the original author(s) and the source, provide a link to the Creative Commons licence, and indicate if changes were made. The images or other third party material in this article are included in the article's Creative Commons licence, unless indicated otherwise in a credit line to the material. If material is not included in the article's Creative Commons licence and your intended use is not permitted by statutory regulation or exceeds the permitted use, you will need to obtain permission directly from the copyright holder. To view a copy of this licence, visit http://creativecommons.org/licenses/by/4.0/.

\section{References}

Arza, V. (2010). Channels, benefits and risks of public-private interactions for knowledge transfer: Conceptual framework inspired by Latin America. Science and Public Policy, 37, 473-484.

Azagra-Caro, J., Archontakis, F., Gutiérrez-Gracia, A., \& Fernández-de-Lucio, I. (2006). Faculty support for the objectives of university-industry relations versus degree of $\mathrm{R} \& \mathrm{D}$ cooperation: the importance of regional absorptive capacity. Research Policy, 35(1), 37-55.

Bourdieu, P. (1975). The specificity of the scientific field and the social conditions of the progress of reason. Information, 14, 19-47.

Bozeman, B., \& Boardman, C. (2014). Research collaboration and team science: a state-of-the-art review and agenda. Springer International Publishing.

Broström, A., Feldmann, A., \& Kaulio, M. (2019). Structured relations between higher education institutions and external organisations: opportunity or bureaucratisation? Higher Education, 78(4), 575-591.

Coleman, J. S. (1990). Foundations of social theory. Cambridge, MA: Harvard University Press.

Dubois, A., \& Gadde, L.-E. (2002). Systematic combining: an abductive approach to case research. Journal of Business Research, 55, 553-560.

Dyer, J. H., \& Singh, H. (1998). The relational view: cooperative strategy and sources of interorganizational competitive advantage. Academy of Management Review, 23, 660-679.

Ek, A.-C., Ideland, M., Jönsson, S., et al. (2013). The tension between marketisation and academisation in higher education. Studies in Higher Education, 38, 1305-1318.

Geuna, A. (2001). The changing rationale for European university research funding: are there negative unintended consequences? Journal of Economic Issues, 35, 607-632.

Gluck, M. E., Blumenthal, D., \& Stoto, M. A. (1987). University-industry relationships in the life sciences: implications for students and post-doctoral fellows. Research Policy, 16, 327-336.

Gulati, R. (1999). Network location and learning: the influence of network resources and firm capabilities on alliance formation. Strategic Management Journal, 20, 397-420.

Hagedoorn, J., Link, A. N., \& Vonortas, N. S. (2000). Research partnerships. Research Policy, 29, $567-586$.

Hagstrom, W. O. (1965). The scientific community. New York: Basic Books.

Inter IKEA Systems (2019). IKEA franchisees. http://franchisor.ikea.com/. Accessed 2 October 2019.

Jacobsson, S., Vico, E. P., \& Hellsmark, H. (2014). The many ways of academic researchers: how is science made useful? Science and Public Policy, 41, 641-657.

Jongbloed, B., Enders, J., \& Salerno, C. (2008). Higher education and its communities: interconnections, interdependencies and a research agenda. Higher Education, 56, 303-324.

Jonsson, A., \& Foss, N. J. (2011). International expansion through flexible replication: learning from the internationalization experience of IKEA. Journal of International Business Studies, 42, 1079-1102.

Larsen, M. T. (2011). The implications of academic enterprise for public science: an overview of the empirical evidence. Research Policy, 40, 6-19.

Lin, M.-W., \& Bozeman, B. (2006). Researchers' industry experience and productivity in university-industry research centers: a "scientific and technical human capital" explanation. Journal of Technology Transfer, 31, $269-290$.

Linnaeus University (2019). Annual report 2018. Ref: 2018/3510-1.2.5. https://medarLinneausre.lnu. $\mathrm{se} / \mathrm{g} 1$ obalassets/dokument\%2 D\% 2 D-gemensamma/universitets ledningenskansli/verksamhetsplanering/linneuniversitetet_arsredovisning_2018_webb.pdf. Accessed 2 October 2019.

Merton, R. K. (1973). The sociology of science- - theoretical and empirical investigations. Chicago \& London: University of Chicago Press.

Parsons, T., \& Platt, G. M. (1973). The American university. Cambridge, MA: Harvard University Press.

Perez Vico, E. (2014). An in-depth study of direct and indirect impacts from the research of a physics professor. Science and Public Policy, 41, 701-719. 
Perez Vico, E., \& Hallonsten, O. (2017). A resource- and impact-based micro-level conceptualization of collaborative academic work. Aslib Journal of Information Management, 69, 624-639.

Perez Vico, E., \& Hallonsten, O. (2019). How industry collaboration influences research: the case of the Swedish interdisciplinary material consortia 1990-2000. Industry and Higher Education, forthcoming.

Perkmann, M., \& Walsh, K. (2009). The two faces of collaboration: impacts of university-industry relations on public research. Industrial and Corporate Change, 18, 1033-1065.

Perkmann, M., Tartari, V., McKelvey, M., et al. (2013). Academic engagement and commercialisation: a review of the literature on university-industry relations. Research Policy, 42, 423-442.

Pinheiro, R., Benneworth, P., \& Jones, G. A. (2015a). Beyond the obvious: tensions and volitions surrounding the contributions of universities to regional development and innovation. In L. M. Carmo Farinha, J. J. M. Ferreira, H. Lawton Smith, \& S. Bagchi-Sen (Eds.), Handbook of research on global competitive advantage through innovation and entrepreneurship (pp. 150-172). Hershey, PA: IGI Global.

Pinheiro, R., Langa, P. V., \& Pausits, A. (2015b). One and two equals three? The third mission of higher education institutions. European Journal of Higher Education, 5, 233-249.

Plewa, C., Galan-Muros, V., \& Davey, T. (2015). Engaging business in curriculum design and delivery: a higher education institution perspective. Higher Education, 70, 35-53.

Slaughter, S., Campbell, T., Holleman, M., et al. (2002). The "traffic" in graduate students: graduate students as tokens of exchange between academe and industry. Science, Technology \& Human Values, 27, 282-312.

Tartari, V., \& Breschi, S. (2012). Set them free: scientists' evaluations of the benefits and costs of universityindustry research collaboration. Industrial and Corporate Change, 21, 1117-1147.

Vahlne, J.-E., \& Jonsson, A. (2017). Ambidexterity as a dynamic capability in the globalization of the multinational business enterprise (MBE): case studies of $\mathrm{AB}$ Volvo and IKEA. International Business Review, 26, 57-70.

Wright, M., Clarysse, B., Lockett, A., et al. (2008). Mid-range universities' linkages with industry: knowledge types and the role of intermediaries. Research Policy, 37, 1205-1223.

Publisher's note Springer Nature remains neutral with regard to jurisdictional claims in published maps and institutional affiliations. 